\title{
La modernización de la educación y la psicologización de los problemas sociales: o de cómo se enseña a las víctimas a culpabilizarse \\ Prof. J esús María Redondo ${ }^{1}$
}

Me gustaria partir con una introducción que situará el tema en el contexto de este Seminario, por esto planteo en primer lugar algunas anotaciones al titulo del mismo.

\subsection{Sobrelacomunidad.}

La situación real de las personas (joven, fracaso escolar, cesante) en nuestra sociedad no tiene causas naturales; sino que deviene del modo de funcionar de nuestro mecanismo de producción y reproducción; porque particulariza unos problemas que, por el contrario, son sociales por su propia estructura y afectan a la relación entre el individuo y la comunidad.

"La estrategia de los derechos/sociedad democráticade derecho-formal/ contratosocial) es un débilsustituto de la disolución de la tradicional solidaridad de clase y de las relaciones basadas en la familia (vinculos de sangre); y en definitiva puede neutralizar la necesidaddesolidaridades nuevas y de espacios y de hugares distintos para construir relaciones interpersonales de tipo comunitario" que intentan recuperar la vinculación social y evitar que "el universalismo jurídico y la economía monetaria, al entregarnos a cadauno de nosotros a la indiferencia del dinero y del derecho abstracto, a la confusión y a la indeterminación de las formas de vida, destruya toda articulación posible de la identidad y de la diferencia". En definitiva puede acabar con la capacidad del reconocimiento del otro que es "el espacio de la relación entre el yo y el otro elque sigue siendo aquel en que ethos y eros están frente a frente; el espacio en elque se puedetenercuinla experiencia del limite que hay que oponer a la concepción moderna de lailimitada manipulabilidad delmundoque hastaahorahaimpedido pensarconcretamente en algo común perteneciente a todos" (Barcellona,P., 1992,108).

Se trata de recuperar la reciprocidad no dineraria; y no se trata, por tanto, de retornar a la comunidad opresiva y autoritaria del antiguo régimen; sino a la comunidad como lugar donde se defiendan y se valoren las particularidades individuales. Supone volver a pensar "la concepción social delindividuo humano y la alienación en tanto mecanismobásico de sus relaciones con la sociedady dela vida en la sociedad' (Schaff, A. 1993,52) Ambas aportaciones originales de Marx (ahora que el marxismo no está de moda). ${ }^{2}$

\footnotetext{
${ }^{1}$ Departamento de Psicología, Universidad de Chile

${ }^{2}$ Para una profundización en los aspectos señalados en este apartado puede consultarse (Redondo J.M. 1995). Capítulo V: "Garantía social en un estado social y democrático de derecho", especialmente los fundamentos del Estado Social Internacionalizado en páginas 277 y ss
} 


\section{2.-Sobre comunidad y subjetividad en América Latina: el rolde lapsicologia.}

Tomando las palabras del Dr. Ignacio Martín-Baró ${ }^{3}$ podemos señalar que el aporte social de la psicología en Latinoamérica es más bien pobre; hay un desencuentro entre la academia y la práctica profesional mayoritaria de los psicólogos por una parte, y las necesidades de las mayorías latinoamericanas por otra.

"En un contexto cultural latinoamericanoquetiendeaconcederunimportante papel a las caracteristicas delaspersonas yalas relacionesinterpersonales; $y q u e$ portantotiende apersonalizary aún a psicologizartodos los procesos, la psicologíatiene unvasto campo de influjo.(...) Y sin embargo, en vez de contribuir a desmontaresesentidocomuindenuestrasculturas queocultayjustifica los intereses dominantes trasmutándolos en rasgos decarácter, lapsicología ha abonado-poracción o poromisión-el psicologismo imperante.(...)Actualmente, con la creciente subjetivización de los enfoques predominantes, lapsicología sigue alimentando el psiclogismocultural ofreciéndose comouna verdadera "ideología de recambio"(Deleule, 1972), (ante el fin de lasideologías). Elpsicologismohaservidoparafortalezer, directao indirectamente, las estructuras opresivas aldesviarlaatención de ellas hacia los factoresindividuales y subjetivos".(Martin-Baro, JL.1998,286).

La psicología latinoamericana ha estadoy/o está esclavizada (Martín-Baró 1998,287-292) de :

a) Un mimetismo cientifista del "hermano mayor" (EE.UU), y sus modas.

b) La carencia de una epistemología adecuada, que está caracterizada por:

a. positivismo: que subraya el como; pero deja de lado el qué, por qué y para qué (parcialización de la existencia humana que le ciega a sus significados más importantes). Es ciego (y por tanto cie- ga a la psicologia) sobre todo para la negatividad (principio dialéctico): "al no reconocermás que lo dado lellevaaignoraraquelloquela realidad existente niega, es decir, aquello que no existe pero que seria históricamenteposiblesise dieran las condiciones" (Martín-Baró 1998,290).

b. Idealismo metodológico: que antepone el marco teórico al análisis de la realidad, no explora los hechos más que en la medida que lo indica la formulación de las hipótesis (muchas veces copiadas de otras latitudes).

c. Individualismo: el sujeto último de la psicología es el individuo como entidad de sentido en si mismo.

d. Hedonismo: partir del supuesto teórico de que detrás de todo comportamiento humano hay siempre y por principio una búsqueda del placer o satisfacción. En el fondo es asumir, al nivel de la subjetividad o de la naturaleza del ser humano, el principio del lucro/máximo beneficio/acumulación que caracteriza el funcionamiento de un sistema socio-económico capitalista.

e. Visión homeostática: recelosa de todo lo que es cambio, desequilibrio; valorar como malo aquello que represente ruptura, conflicto, crisis, violencia. Los desequilibrios inherentes a las luchas sociales pueden ser interpretados, y de hecho lo son, como trastornos personales; $y$ los conflictos generados por el rechazo al ordenamiento social como patológicos.

f. Ahistoricismo: Evidenciado en el uso de instrumentos de medida, test (CI), DSM IV, etc, de forma transcultural, sin consideraciones contextuales e históricas suficientemente críticas yadecuadas.

${ }^{3}$ Psicólogo y sacerdote jesuita asesinado en el Salvador hace unos años, en un artículo escrito en 1986 y titulado:"Hacia una psicología de la liberación”. 


\section{3.-Elfondo de la violencia (releer a Rene Girard, 1972-1978) ${ }^{4}$}

\section{a) La fatal ambigüedad de la violencia:}

La violencia es experimentada como buena y necesaria, precisamente porque sólo ella es capaz de afrontar y vencer a la violencia. Pero es maléfica y fatal porque, en su enfrentamiento con la violencia, desencadena siempre otras violencia nuevas (entre las que ya está ella misma).

Este proceso es tan inevitable que es independiente de la buena o mala voluntad de los violentos. La lógica es coherente: precisamente por que se teme a la violencia, hay que oponerse a ella. Cuanto más se la quiere dominar, más se la alimenta.

b) La víctima emisaria: acto creador de la comunidad / sociedad.

Los hombres no son capaces de reconciliarse más que a expensas de un tercero. (canalizar la violencia de todos hacia fuera del grupo). Acontece la necesidad del sacrificio como la única violencia sin riesgo de venganza.. Es preciso un Enmascaramiento/ocultamiento: la eliminación de la víctima no debe creerse que es obra de la violencia sino de un imperativo absoluto. La víctima debe parecerse y ser diferente a los miembros del grupo.

c) La institucionalización del sacrificio y su crisis.

En todas las instituciones humanas se trata siempre y en primer lugar de reproducir ese linchamiento reconciliador por medio de nuevas víctimas.

La crisis del sacrificio/víctima es la pérdida de la diferencia entre violencia impura y violencia purificadora. Es una crisis de las diferencias. En este marco se inscribe la aparición de la transgresión como fenómeno social. En él la violencia reciproca destruye todo lo que la violencia unánime había edificado. Entonces: "ya noes el valorintrinseco del objetoloque provoca el conflictoal excitarlos deseos rivales, sinoque sla violencia mismalaque valoralos objetos inventandopretextos paradesencadenarsemás" (Girard R., 1972,292). Ella dirige el juego y se ríe sucesivamente de todos.

\author{
d).En la raíz . el deseo mimético.
}

"Nosonlos deseosdelos hombresquienes entranen conflicto, sino que son los conflictos quienes hacen coincidirlos deseos" (Gonzalez Faus, JL.1998, 241): "el sujeto desea elobjeto porque el rival también lo desea." (Girard, R. 1972,204). ¿Tendrá esto algo que ver con las estrategias de la publicidad en la actual sociedad de consumo?.

De modelo a imitar a rival (Edipo): "El objeto del deseo es el objeto prohibido, no porla ley (Freud), sinoporaquélquenosloseñalacomodeseablealdesearloél mismo" (Girard, R. 1978,320) (doble vinculo).

"El niñopropiamentenotiene conciencia del modelo comorival, nideseode usurpaciòn propiamentetal. $;$ Es el modelo quien hace esa lectura!" (Gonzalez Faus, JL.1998,242).Asi “eldiscípulosecreeculpablesinsaber exactamentedequeselejuzga;indignodeposeer lobjeto que desea.(...)Asíseesbozalaorientacióndel deseo hacia objetos protegidos porla violencia del otro. El lazoquese ataaquientrelodeseableylaviolenciapuedequeyanose desatenunca' (Girard,R. 1972,243; 1978,320).

Pero esto tiene también una lectura cultural. La cultura actual (de consumo globalizada) "dispara el deseo yno solocarece de recursos para satisfacerlo, sino queinchuso niega a muchos aquellos objetos que ofrece como solución para el deseo, mientras propone como modelos a los pocos aforturnados que acapararonesas presuntas soluciones. Deformaqueestemecanismode liberación del deseo mimético hace que nuestro mundo sea ala vez enormemente creadory enormemente angustiado:ambascosas."(GonzalezFaus,JL. 1998,243).

Los modernos se imaginan siempre que sus angustias y sus disgustos provienen de las trabas que e oponen al deseo los tabúes religiosos, las prohibiciones culturales y las protecciones legales de los sistemas judiciales, incluso en nuestros dias: "Piensanqueunavezdembadasesas bamerasseexpansionará el deseo: su maravillosa inocencia daráporfin sus frutos.

${ }^{4}$ Realizamos una presentación esquemática a través de la presentación del pensamiento del autor y de las traducciones de los textos de(Gonzalez Faus, JI. 1998, 299 ss). 
Peroestoruncaes verdadero. A medidaqueeldeseo eliminalosobstáculos exteriores, sabiamente dispuestos por la sociedad tradicional para prevenirlos contagios deldeseo, el obstáculo vivo del modelo, inmediatamente convertido en rival, sustituirá a la prohibición desafianteconventaja(o mejorcon desventaja). En hugardeaquel obstáculoinerte, pasivo, benévolo poridéntico para todos $y$, por eso, nunca seriamente humillante $y$ traumatizador, los hombres se encuentranconelobstáculo activo, móvil y feroz, del modelo metaforseado en rival. Un obstáculo activamente interesado en contradecirles personalmente, y maravillosamente equipadopara conseguirlo.

Ensuma:cuantomáscreenlos hombres realizarsus utopías del deseo, cuanto más abrazan ideologías liberadoras, mástrabajan en realidad proel perfecciona- miento de un universo competitivo en cuyo seno se ahogan... Lamejormaneradecastigaraloshombresesdarles siempreloquepiden... Todoelpensamientomodernoes falseado por la mística de la transgresión, en la que cae inchusocuandoquiere escapardeella. En Lacaneldeseoes instauradoporlaley. Y hastalos másaudacesde muestros días no reconocen lo esencial, que es la función protectora delaprohibición frente a los conflictos que provocainevitablementeeldeseo. Tendrianmiedodepasarporreaccionarios silohicieran.

Enel pensamientoque nos dominadesde hacecien años, noconvieneolvidar el miedo a pasarporingenuoy sometido, el deseode jugar a liberado o a revolucionario: deseoque bastacon halagarpara hacerdecircualquier cosaalos pensadores modernos." (Girard, 1978,310311).

\section{2.- MODERNIZACIÓN DE LA EDUCACION Y PSICOLOGIZACIÓN DE LOS PROBLEMAS SOCIALES.}

\subsection{Contexto: Tres aspectos adestacar.}

Primeramente, se afirma que estamos ante/en/ dentro de una época de mercado mundial único, de globalización cultural, de fin de siglo/milenio; de crisis de civilización o epocal; de fin de la historia. ¿Qué caracteriza esta época o transición?.

Coinciden muchos autores en señalar como el aspecto central el paso de la sociedad del trabajo a la sociedad de la cesantia, a la civilización del desempleo. Esta realidad implica el fin del mito industrialista de la sociedad del trabajo; el fin de la sociedad keynesiana del bienestar, de la integración social por el trabajo (integración económica) y la educación (integración simbólica). Ambas integraciones legitiman la democracia capitalista; y por tanto su crisis desemboca en una crisis de los valores, la cultura, las leyes que contienen la violencia. La legalidad democrática no se legitima en las conciencias de los individuos. (Redondo, JM. 1995, 9-50).
En segundo lugar, esta constatación remite, en el fondo, a una conexión que es importante desvelar, y que está presente cuando se formula el titulo de este seminario. Y se refiere a la relación entre "estructura social" y "subjetividad" (Joignant, A 1998). Es una problemática epistemológica, y por tanto política y ética.

Se habla hoy de : "la construcción social de las subjetividades", "la subjetivización de las estructuras sociales", "la construcción social de la realidad", e incluso de "la realidad/virtualidad de las construcciones sociales". Cualquiera de estas posiciones trae, en el centro, desde todos las áreas del conocimiento ( antropologia, sociologia, psicología, lingüistica, pedagogía, biologia, etc.) el tema de la "cognición": sea esta entendida como cognición social, biológica o psicológica. Se habla de las ciencias cognitivas ( teoria de sistemas, lin- 
güistica, procesamiento de la información, PNL, Redes neuronales, redes sociales o incluso comunitarias, etc.)

Por último, la transmisión de la cultura y/ o la educación se fundamenta metodológicamente, en alguna de estas opciones "epistemológicas". Hoy asistimos a una crisis triple en este campo de las transmisiones (Duch,LL. 1997, 13-84):

\section{a)Crisis de las estructuras deacogida(lugares} y tiempos de desarrollo/creación de la cognición social, biológica y psicológica: familia, escuela, comunidad local).

b) Crisis de la tradición ( tradere, transmitere) reflejada en: a) somos seres de memoria (oral, pala- bra, logos, narración,etc.) en crisis. b) Se ha ido produciendo a lo largo de toda la modernidad una excisión entre sabiduria y ciencia. c) Asistimos a una perversión de la tradición en poder (de autoritas a autoritarismo).

c)Crisis pedagógica acotada por: a) los mensajes de las estructuras de acogida no son creíbles (¿qué papel ha jugado la introducción, en sus tiempos y lugares, de los medios de comunicación?). b) se da, progresivamente, un agotamiento del poder (evocador, invocador, convocador, provocador) de las palabras, que son sustituidas por acciones e imágenes no elaboradas ( $(\dot{c})$. c) Nos encontramos en un proceso de deseuropeización de la cultura, y los sistemas educativos están basados en ella.

\subsection{Modernización de la educacióny/o psicologización delos problemassociales.}

La modernidad ha degenerado en mera racionalidad técnica. Esta racionalidad realiza una neutralización del mundo; "la realidad ya no está constituida porcosas sino porrelaciones" (Galimberti, cit. Barcelona, 1992,16). De forma que la ciencia y la teoría autolegitiman la técnica desde el criterio de la eficacia del resultado. Por este camino se llega a que " la modermidadnosabeofrecerningúnterrenocomúnqueno sealaneutralizacióndelatensiónentrelas diferenciasindividuales en la formadelintercambio mediadoporel dinero" (Barcelona, 1992,20). En el mercado global. A esto se llama modernización. En este nuevo contexto de desacralización o relativización de todo (post-modernidad), curiosamente, queda divinizado e idoltrado el mercado y el dinero, con su liturgia de consumo que consume al consumidor. ${ }^{5}$

Modernizar la educación es precisamente hacerla capaz de dar respuesta a estos desafios actuales de la modernidad/postmodernidad:
- Desafios económicos, desde la globalización del mercado ( productividad, creatividad, valor añadido, tecnologia).

- Desafios políticos, desde la democracia formal (ciudadanía, legitimidad, control del poder).

- Desafios culturales, de reconstruir valores, actitudes, normas y simbolos (etica-moral, integración social, desarrollo personal).

Se requiere, ciertamente, otro modelo escolar más tecnificado, mas racional, más neutro (tolerante), más democrático. Se requiere otra pedagogia, más constructivista, más activa, más comunitaria. Pero es imposible responder al mimos tiempo a todos los requerimientos económicos, politicos y culturales; ya que son contradictorios.

La reforma educativa actual en Chile parte, en el contexto señalado, con una ambigüedad estructural: la ambigüedad de la descentralización (de la gestión y curricular) como forma de conseguir más equidad y más calidad. ${ }^{6}$

\footnotetext{
${ }^{5}$ Para una profundización de estas reflexiones puede acudirse a lo citado en la nota primera, explictamente al apartado referido al "mito de la modernización".

${ }^{6}$ Un desarrollo mayor de esta ambigüedad puede encontrarse en (Redondo JM. 1995), y sobre todo para el caso chileno en (Redondo,JM. 1997, 15-17).
} 
La dinámica escolar es estructuralmente un proceso que transforma las diferencias en desigualdades, a través de: a) La desigualdad y uniformidad de trato de las diferencias de los alumnos, desde las expectativas sociales de los agentes de la educación, especialmente de los profesores. b) El diseño de la tarea basado en la normalización, más que en el logro. c) La evaluación normativa y no criterial.

Desde esta dinámica social y escolar, la subjetividad de los jóvenes/alumnos se estructura caracterizada por: a) Vivencia del éxito como propio, bien por la posesión de capacidades "naturales", bien por el mérito de aguantar la escuela tanto tiempo. b) Vivencia del fracaso escolar como fracaso personal, pérdida de la oportunidad, culpabilizandose por la ausencia de capacidades "naturales", o por no haber aguantado la escuela más tiempo.
La opción por la exclusión (subcultura delabandono escoar) resuelve de modo imaginario los problemas que, a nivel material, permanecen sin resolver. La convergencia de la cultura obrero-popular, la cultura postmoderna del ocio-consumo adolescente y la subcultura delictiva se presenta como el único espacio de supervivencia para estos jóvenes (Redondo, JM. 1998)

En el fondo los adolescentes parecen ser conscientes del valor de uso real de la oferta educativa que consumen: aparcamiento y control social sin proyección de futuro; $y$ buscan alternativas al menos para el hoy, aquíy ahora (subsistencia). La subjetividad de la subsistencia sin proyecto de futuro, sin proyecto de vida. (Redondo, JM. 1995).

\section{3.- DE COMO SE ENSEÑA A LAS VICTIMAS A CULPABILIZARSE}

La institución escolar tiene sus víctimas "ocultas" que la mantienen como mecanismo de legitimación de las desigualdades sociales basadas en las diferencias "naturales" o presuntamente decididas (abandono escolar).

Las victimas han experimentado o el rechazo autoadjudicado, o la decisión de abandonar. Han sido marcados por fuera (título o certificación escolar) y por dentro (autoconcepto); justo en la edad (adolescencia-juventud) en la que se define la propia identidad, pertenencia y proyecto de vida.

En las víctimas/fracasados escolares podemos encontrar la lógica real del sistema más allá de los discursos, las intenciones o los derechos y leyes. Se ha materializado la violencia constitutiva de la legitimidad del sistema social. Y se ha materializado no solo en la estratificación social por el mérito escolar/ titulo; sino también en las conciencias o subjetividades de los individuos; tanto para los que tienen éxito como para los que fracasan. Realizando asi una psicologización y subjetivización de una problemática que es esencialy estructuralmente social.
Pero me interesa una última palabra sobre la culpabilidad como elemento que está a la base de la cultura humana; en recuerdo de Freud y su "malestar de la cultura-civilización".

La existencia de cultura, de comunidad más allá del gregarismo; tiene el precio de la represión de los deseos biológicos y subjetivos o su tranformación sublimada en deseos culturales y sociales (aceptados). Esta transformación utiliza el mecanismo de la culpabilización, mecanismo que se aprende en el propio proceso socio-cultural personal (creación/desarrollo de la cognición). En su origen es miedo a la pérdida de la relación de amor, pérdida del reconocimiento del otro a mi yo como otro valioso para él; o miedo a la perdida de la lógica del don y la gratuidad (P. Ricceur). La experiencia del doble vínculo (lógica del don, lógica de la justicia).

Pero también, al mismo tiempo, es la realización del proceso de renuncia a la omnipotencia de los deseos y pensamientos, adentrandose en el misterio de la alteridad, la reciprocidad, el diálogo con el 
otro yo; en la comunidad y hacia lo real; dentro del conflicto e incluso de la violencia y la muerte. Ni la religión (aparentemente antigua y caduca), ni la nueva religión de la ciencia y la técnica y su gran dios el mercado, pueden responder a ese deseo de omnipotencia.

Es por esto que

"recurrir a lo fragmentario como terreno donde se asientalohumano; ajustarse alatimitación(delamuente sobretodo) como bordequela realidad impone yquees necesario aceptar, apelaralo simbólico comoordenenel quelapresenciasecombinaconausencia, necesariamente, yloconquistado con lo perdido; aceptar, en definitiva queenlaesenciadelohumanose inscribe unacarencia quenadaninadiepuedellenar, nosignificaresignarsea unorden decosas en elque el sueño y la fantasía, el proyecto y la utopía notengan ya alcance ni significación. Sencillamente es trata de proporcionaraesos sueños $y$ fantasias, a esos proyectos utópicos, elúnico hugardondepuedenecharfirmes raices:tierracomolugaridóneo parael hombre ycomoúnicotugardondepuedeadvenir Dios".(Domínguez, C. 1990,506)

\section{Bibliografia}

Barcellona, P. (1992) "Postmodernidad y Comunidad. El regreso del vinculo social”. Barcelona: E. Trotta. Deleule, D. (1972). "Psicología y mito científico". Barcelona: Anagrama.

Dominguez, C. (1991) “Psicoanálisis freudiano de la religión”. Madrid: Ediciones Paulinas.

Duch, LL. (1997) “La educación y la crisis de la modernidad”. Barcelona: Paidos.

Girard, R. (1972) “La violence et le sacré” Paris: Grasset.

Girard, R. (1978) “Des choses cachées depuis la fondation du munde”. Paris: Grasset.

Gonzalez Faus, JI. (1998) “Fe en Dios y construcción de la historia”. Madrid: E. Trotta.

Joignant, A. (1998) "Agente, estructura y cognición. Preguntas de investigación a partir de la sociología de Pierre Bourdieu y Anthony Giddens" en Perspectivas Críticas en Teoria Politica. Centro de Investigaciones Sociales. Documento de Trabajo $n^{0} 26$. Universidad ARCIS..

Martín-Baró, JL. (1998) “Psicología de la liberación”. Madrid: E. Trotta.

Redondo, JM. (1995) “Análisis de la situación social de los jóvenes desfavorecidos y propuesta de un programa integral de garantía social” Tesis doctoral. Edición Microficha. Bilbao: Universidad de Deusto. Redondo, JM. (1997) “La dinámica escolar: de la diferencia a la desigualdad”. Revista de Psicología Universidad de Chile. Vol VI.; 7-18.

Redondo, JM., y otros (1998) “El mundo de los jóvenes y la reforma de la enseñanza media. La necesidad y la posibilidad de construir comunidades educativas autónomas y responsables". Revista de Psicología Universidad de Chile. Vol VII. 35-50.

Schaff, A. (1993) “Humanismo Ecuménico” . Barcelona: E. Trotta. Artículo de ARCIS. 


\section{Prof.LauraMoncada, Presentación de Hugo Rojas}

El Profesor Hugo Rojas, Psicólogo y Psicoterapeuta Psicoanalítico, es docente del Area Clínica desde la perspectiva psicoanalitica en nuestro Departamento y además Director del CAPs. (Centro de Atención Psicológica). Desde su lugar como psicoterapeuta, nos presenta una reflexión sobre la agresión en el vinculo terapéutico y su relación con la cultura. 